\title{
CONTAÇÃO DE HISTÓRIAS NA EDUCAÇÃO INFANTIL E AS TECNOLOGIAS COMO FERRAMENTAS PEDAGÓGICAS
}

\author{
Fabiula Candida da Silva ${ }^{1}$ \\ Luis Gabriel Venancio Sousa ${ }^{2}$
}

\section{RESUMO}

Esta pesquisa tem como objetivo geral investigar se e como as tecnologias digitais são apresentadas em propostas pedagógicas de contação de histórias para crianças da Educação Infantil. Abordar a contação de histórias na Educação Infantil e as tecnologias como ferramenta pedagógica torna-se relevante porque as histórias, quando contadas, permitem que professores interajam com o seu educando, podendo despertar o gosto pela leitura e, com isso, colaborando para a formação de leitores. Além disso, investigar como tecnologias digitais podem ser usadas na práxis docentes é importante, uma vez que diversos artefatos fazem parte do cotidiano das crianças. Nesse contexto, o presente estudo consiste em pesquisa de caráter qualitativo de cunho interpretativista. Para tanto, os dados para a análise foram gerados no site da Revista Nova Escola, onde foram selecionadas dez propostas, indicadas para professores que atuem na Educação Infantil, cuja abordagem fosse relacionada a práticas de contação de histórias. Teoricamente, nos ancoramos nos estudos de Abramovich (2009), Kenski (2007), Coelho (1999), entre outros. Como resultados, aventamos que a contação de histórias é utilizada nas propostas pedagógicas como sinônimo de leitura. Ademais, identificamos que as tecnologias, em sua grande maioria, são aquelas analógicas, tidas, aparentemente, como tradicionais, deixando as tecnologias digitais ainda de forma tímida como recurso para a contação de histórias.

Palavras-chave: Educação Infantil. Contação de Histórias. Tecnologia.

${ }^{1}$ Graduada em Pedagogia pela Faculdade Unina. E-mail: fabiulacandida@hotmail.com 2Doutorando em Linguística (UFSC), Mestre em Estudos de Linguagens (UTFPR), Professor na Faculdade Unina. E-mail: Iuis.gabriel@unina.edu.br 


\section{ABSTRACT}

This research aims mainly to investigate if and how digital technologies are presented in pedagogical proposals for storytelling for children in Early Childhood Education. Addressing the storytelling in Early Childhood Education and technologies as a pedagogical tool becomes relevant because the stories, when told, allow teachers to interact with their students, and can bring the taste for reading and, thus, contributing to the formation of readers; furthermore, investigating how digital technologies can be used in teaching praxis is relevant, since several artifacts are part of children's daily lives. In this context, the present study consists of a qualitative research of an interpretative nature. For this, the data for the analysis were generated on the website of Revista Nova Escola, where we looked for ten proposals, indicated for teachers who work in Early Childhood Education, whose approach was related to storytelling practices. Theoretically, we have been inspired by the studies of ABRAMOVICH (2009), KENSKI (2007), COELHO (1999), among others. As results, we would like to show that storytelling is used in pedagogical proposals as a synonym for reading, in addition, we identified that the technologies, for the most part, are analog technologies, apparently considered as traditional, leaving digital technologies still timidly as a resource for storytelling.

Keywords: Early Childhood Education. Storytelling. Reading. Technology.

\section{INTRODUÇÃO}

Esta pesquisa tem como objetivo geral investigar se e como as tecnologias digitais são apresentadas em propostas pedagógicas de contação de histórias para crianças da Educação Infantil. Ela parte da seguinte questão-problema: Se as crianças contemporâneas estão imersas em uma sociedade digitalizada e algumas de suas ferramentas de interação são tecnologias digitais, estariam essas tecnologias sendo contempladas no contexto escolar das crianças, principalmente na contação de histórias?

Por estar inserida no âmbito de uma pesquisa em ciências humanas, optamos por uma abordagem qualitativa, que, segundo Creswell (2007, p. 186), é fundamentalmente interpretativa, isto é, não pressupõe que a realidade é dada, ela é uma construção da pessoa que está vivendo ou observando um determinado fenômeno (CRESWELL, 2007). 
A dinâmica de geração dos dados para responder ao proposto na pesquisa ocorreu da seguinte forma: em primeiro lugar, foi acessado o site da Revista Nova Escola em busca de propostas pedagógicas elaboradas para professores que atuam com crianças da Educação Infantil, a fim de entender e analisar se há ou não indicação de tecnologias digitais como instrumentos para as práticas de contação de história.

A escolha pelo site se deu por ele ser aberto a consultas e disponibilizar propostas pedagógicas alinhadas à BNCC, para professores de diversas modalidades da educação básica, inclusive aqueles que atuam na Educação Infantil.

Quanto aos critérios de busca e geração dos dados analisados posteriormente, pesquisamos propostas pedagógicas atribuídas e direcionadas aos professores da Educação Infantil. A partir disso, foi feita uma busca com o verbete contação de histórias. Foram selecionadas 10 propostas pedagógicas que contemplam contação de histórias para compor os dados da pesquisa.

Na próxima seção, apresentamos nossa ancoragem teórica, para, depois, elucidar os resultados encontrados.

\section{APORTE TEÓRICO}

Kenski (2007) diz que as TICs transformam comportamentos na forma de viver, trabalhar e de se organizar. Essas alterações tecnológicas’ se ramificaram por todas as atividades e setores da sociedade, de forma a refletir na nossa forma de comunicação e, com isso, impulsionaram o consumo e o aparecimento de "ambientes virtuais interativos" (KENSKI, 2007, p. 111). Hoje, grande parte da comunicação se dá pelos telefones celulares, que "redimensionam nossas disponibilidades temporais e nossos deslocamentos espaciais" (KENSKI, 2007, p.

\footnotetext{
1 Tomamos como conceito de tecnologia nesta pesquisa a concepção de Cupani (2016): tudo aquilo que podemos planejar, isto é, tudo que somos capazes de abstrair por meio da linguagem, aliado ao planejamento, vai resultar na tecnologia, como, por exemplo, a fogueira, que está na natureza e foi planejada e elaborada pelo homem a partir da descoberta do fogo a fim de aumentar a sua durabilidade. Pode-se resumir, portanto, que tudo o que o homem é capaz de planejar e transformar é tecnologia.
} 
26).

Essas transformações impactaram na educação. Quanto a isso, Kenski (2007) explica que, antigamente, a aprendizagem era uma tarefa exclusiva da escola, onde as informações eram passadas no quadro com giz, mas hoje se expandiu para a cibercultura, por meio da qual os papéis dos professores e das escolas foram sendo modificados, o que trouxe uma ressignificação na forma de aprendizagem.

No ciberespaço, a forma tradicional de conhecimento, que ficava a cargo do educador, passa a ser acessada por meio da comunicação de massa, que abre várias possibilidades para se chegar ao conhecimento e à aprendizagem.

Portanto, podemos considerar que essas alterações também ocorreram no âmbito da Educação Infantil, com o uso das tecnologias digitais pela criança. Antes mesmo de elas serem alfabetizadas ou aprenderem a falar, já ouvem músicas, assistem a desenhos, jogam videogame, acessam canais do Youtube, tudo isso com o acesso à internet por dispositivos digitais.

Nesse contexto, adotar os recursos usuais no cotidiano das crianças como ferramenta pedagógica, levando-os para a sala referência, é uma forma de aproximação desses mundos, mas, ao mesmo tempo, preocupante. Quanto a essa preocupação, Kenski ressalta que "nem tudo são maravilhas no uso das tecnologias na educação" (2007, p. 53). Ela enfatiza a necessidade da manutenção e segurança, porque a internet traz muitos problemas inadequados, como: muito tempo jogando, acesso facilitado a site impróprio e a segurança dessa criança que fica exposta em ambientes em que a exploração, o assédio e o abuso sexual ocorrem cada vez mais frequentemente.

Segundo Kenski, o papel da escola surge em "garantir aos alunos-cidadãos a formação e a aquisição de novas habilidades" (2007, p. 64), logo, adotar esses recursos como ferramentas pedagógicas na Educação Infantil e aproximar o educador da realidade dessas crianças é necessário e urgente.

Essa inserção de tecnologia na Educação Infantil é um cenário novo comparado a outros segmentos. Assim, é muito importante que os professores desenvolvam habilidades para atuar no mundo de hoje. 
Para Kenski (2007),

Para que as TIC possam trazer alterações no processo educativo, no entanto, [...] elas precisam ser compreendidas e incorporadas pedagogicamente. Isso significa que é preciso respeitar as especificidades do ensino e da própria tecnologia para poder garantir que o seu uso, realmente, faça diferença. Não bastar usar a televisão ou o computador, é preciso saber usar de forma pedagogicamente correta a tecnologia escolhida (p. 46).

Desse modo, faz-se necessário trazer para o contexto de ensino da Educação Infantil as práticas digitais que elas têm fora dos muros escolares não apenas como uma ferramenta, mas, principalmente, com reflexão de eficácia de seu uso para as atividades pedagógicas.

Assim sendo, é relevante pensarmos e compreendermos as relações que as crianças estabelecem em diferentes contextos sociais, mediados pela família, escola, cultura e pelos artefatos tecnológicos em particular. A relação da criança na Educação Infantil há vinte anos era muito diferente do que vemos nos dias de hoje. Vale ressaltar que vinte anos atrás os artefatos tecnológicos digitais não estavam inseridos na vida dessas crianças na forma como vivenciamos atualmente, porque antigamente o professor utilizava mais tecnologias analógicas. Por isso, estabelecer uma proximidade cada vez maior entre o mundo real e a escola torna-se cada vez mais urgente e necessário.

À vista disso, no ano de 2020, a pandemia da Covid-19, causada pelo novo coronavírus, fez com que a escola, da modalidade presencial, tivesse a necessidade de reinventar a forma de ensinar, evidenciando que a aprendizagem não está só no espaço físico escolar. E esse cenário pandêmico materializa o que Kenski (2007) destaca ao dizer que o mundo vem desenvolvendo várias formas de tecnologias, e o papel da educação seria socializar e inovar, logo, tecnologia e educação são indissociáveis.

Para orientar os agenciamentos de ensino na Educação Infantil, o Ministério da Educação (MEC, 2020) solicita que o educador busque uma aproximação virtual de forma lúdica a fim de que essa criança se desenvolva brincando.

Desse modo, é relevante pensarmos que a contação de histórias² é uma 
ferramenta pedagógica, podendo ser amparada por tecnologias analógicas ou digitais. Se a criança tem acesso a desenhos animados, o que podemos considerar aqui como contação de histórias, e vídeos do Youtube, é relevante se questionar se a escola está acompanhando essas mudanças de comportamento da criança fazendo uma aproximação virtual que propicie a aprendizagem.

Apresentada esta breve reflexão sobre tecnologia e educação, na próxima seção, elucidamos os resultados da pesquisa.

\section{RESULTADOS ENCONTRADOS}

Nesta seção, refletimos a respeito de se/como tecnologias digitais são indicadas em propostas pedagógicas de contação de histórias para crianças da Educação Infantil.

Foram analisadas 10 propostas lotadas no site da Revista Nova Escola, cujo público-alvo fossem professores da Educação Infantil, contemplando a temática "contação de história." Vale destacar que essas propostas são elaboradas por professores e estão rotuladas como recursos educacionais abertos (REAs 3).

É importante ressaltar que utilizamos como recorte temporal os anos de 2017 a 2019, contudo trazemos uma proposta do ano de 2007 justamente para elucidar se esse outro espaço-tempo pode interferir na inserção de tecnologias digitais na Educação Infantil.

Inicialmente, identificamos que todas as propostas pedagógicas respondem a uma estrutura de texto padrão, que provavelmente pode ser indicado

\footnotetext{
2 Não consideramos, nesta pesquisa, a perspectiva de contação de histórias e leitura como sinônimas. Adotamos a concepção de contação de história apoiada nos estudos de Abramovich (2009): "ler é entender a histórias através do autor, já contar histórias é necessário, porque cria um clima de envolvimento, e quando se coloca vozes se dá vida à história". ${ }^{3}$ REAs são materiais de ensino elaborados e disponibilizados em rede para a uso na educação. Além disso, não há direitos autorais, pois também surge na proposta de movimento ou comunidade internacional, que tem como objetivo elaborar e promover o acesso, uso, remixagem e reuso de REAs, com base na ideia de bens comuns.
} 
pelo site.

Isto posto, todas as propostas analisadas, por exemplo, contêm o título da proposta, como também o campo de experiência que será trabalhado pelo educador, o nome do autor e o objetivo que se pretende atingir, bem como a idade adequada para a atividade, além de sugestões de materiais/recursos a serem usados pelo educador na sala de referência.

A partir disso, não foi possível identificar se essas propostas são atualizadas $^{4}$ depois do momento em que são postadas no site. Atualmente, como as tecnologias digitais evoluem muito rápido, não ter essas propostas atualizadas pode ser um problema, porque os recursos indicados nas propostas pedagógicas podem ficar ultrapassados muito rapidamente.

A fim de elucidar essa afirmação, selecionamos uma proposta do ano de 2007, onde observamos que não há uso de tecnologias digitais, por exemplo. Essa proposta está organizada com o intuito de desenvolver a criatividade, o respeito pela fala do outro e o discurso narrativo indicado para crianças de quatro anos. Ela não indica o uso de tecnologias digitais, apenas livro, fantoche e fantasia. Em 2007, as tecnologias digitais ainda não tinham uma popularidade tal como vemos hoje, com tabletes, celulares com internet etc.

A figura 1, na sequência, mostra a estrutura organizada da seguinte forma: idade, tempo, espaço, material e objetivos. No campo materiais, é possível perceber que não há indicação de recursos digitais.

FIGURA 1 - Proposta 2007

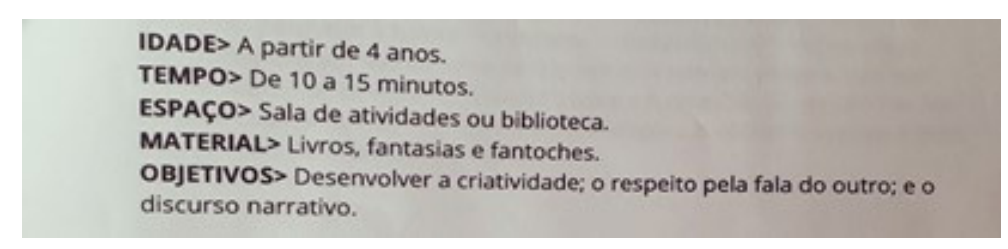

Fonte: Nova Escola (2007)

\footnotetext{
${ }^{4}$ No período de pandemia, tempo em que esta pesquisa foi escrita, o site disponibilizou propostas voltadas exclusivamente para o ensino remoto.
} 
Das outras propostas analisadas, percebemos que quatro delas trazem tecnologias digitais como indicação de recursos pedagógicos. Ainda que elas não sejam recorrentes em todas as propostas, são tecnologias que possivelmente já estão presentes no cotidiano dessas crianças, logo, essas ferramentas possibilitam a proximidade das atividades com o mundo fora da escola. Os instrumentos indicados foram: instrumento sonoro, equipamentos para filmagem, equipamento para foto, celular e televisão.

A figuras 2, 3, 4, e 5 ilustram como essas tecnologias foram apresentadas, na seção materiais.

FIGURA 2 - Proposta com materiais tecnológicos1

\section{O que fazer antes? \\ Contextos prévios:}

Para esta proposta é importante que você tenha apresentado ao grupo histórias que utilizem sons corporais ou instrumentos musicais com a narrativa. Familiarize o grupo com a utilização de sons, construindo um repertório de sonorização.

Por exemplo, na história dos Três Porquinhos, o sopro e a queda de cada uma das casas são momentos da narrativa que podem ser sonorizados. No livro Cadê o Pintinho, de Márcia Leite, publicado pela editora Pulo do Gato, cada aparição dos animais pode corresponder a um som, feito com o corpo ou com instrumentos.

Depois de garantido esse repertório do uso de sonoplastia com histórias, escolha uma uma para ler e separe-a em partes, para planejar a sonorização com as crianças.

\section{Materiais:}

Planeje os materiais sonoros conhecidos do grupo, considerando a história que será lida. Você pode prever materiais como instrumentos musicais convencionais que sejam acessiveis ao grupo, utilizar instrumentos confeccionados artesanalmente ou pelas próprias crianças, outros objetos que produzam sons ou usar um repertório sonoro produzido com o corpo. O repertório de sons do corpo pode ser representado em fichas, por meio de figuras que lembrem a ação necessária para a reprodução do som.

\section{Espaços:}

Preveja um espaço para uma roda de história. Busque um local sem muita interferência sonora, tendo em vista o cuidado para não comprometer a sonorização da proposta.

Planeje a organização da turma em pelo menos dois grupos, para que as crianças manuseiem os instrumentos e possam interagir. Caso não seja

Fonte: Nova Escola (2018a).

\section{FIGURA 3 - Proposta com materiais tecnológicos 2}

\section{Contextos prévios:}

Para esta proposta é fundamental que você conheça o livro Tem de tudo nesta rua..., do autor Marcelo Xavier, da Editora Formato. O livro retrata cenas do cotidiano vividas por personagens que trabalham nas ruas como o pipoqueiro, o camelô, o lambe-lambe, com um texto cheio de poesia. As ilustraçōes, criadas em massinha de modelar e, depois, fotografadas, encantam o leitor pela riqueza de cores e detalhes, tornando assim, a leitura ainda prazerosa. É fundamental que você se aproprie da narrativa e envolva seu olhar na contemplaç̃o das imagens, percebendo que a escolh
livro interage com a poesia da narrativa, trazendo uma visão sensivel e rica de cenas do cotidiano.

\section{Materiais:}

Além do livro, você precisará para esta proposta, de massa para modelar. Considere a mais adequada para seu grupo de crianças. Organize também, materiais que auxiliem na modelagem, como palitos de vários formatos, rolos, formas de molde e outros instrumentos. Considere um equipamento para registrar fotografias do grupo em interação com a atividade.

\section{Espaços:}

Antecipe um espaço para um pequeno grupo de crianças, acolhedor e confortável para a leitura do livro, de forma que as elas consigam observar as imagens da obra. Prepare, também, um espaço de ateliê com as massinhas e instrumentos de modelagem suficientes para o grupo

Para o grupo de criança que não estará envolvido na proposta, prepare uma atividade que já realizam com autonomỉ tois como jogos e brinquedos de encaixe, por exemplo.

Fonte: Nova Escola (2018b). 
FIGURA 4 - Proposta com materiais tecnológicos 3

\title{
Contextos prévios:
}

Este plano faz parte de uma sequência de cinco. São eles:

1. A proposta de um livro de receitas

2. Explorando o texto da receita

3. Escolha das receitas que vão para o livro

4. Fazendo uma receita

5.

\section{Materiais:}

Separe as receitas trazidas pelas crianças e escolha uma para cada pequeno grupo montar. Para isso escreva-a ou digite-a e imprima uma cópia dela (com letra de forma maiúscula) e a corte em partes (título, ingredientes, modo de fazer, ilustração), seguindo este modelo. Leve cola, papel para colar a receita montada e papéis com outros tipos de texto (como cartas, narrativas, parlendas, tirinhas etc). Providencie material para anotação e, se preferir, equipamento para gravar as falas das crianças e transcrevê-las depois. Disponibilize materiais para as atividades de livre escolha, como massinha, uma cozinha com diferentes utensílios e embalagens (para brincarem de faz de conta) e jogos de montar. Providencie aparelho de som ou celular se quiser usar a sugestão de música do Para Finalizar.

\section{Espaços:}

Para esta atividade, as crianças estarão divididas de duas maneiras: a maioria estará transitando livremente pelas ativiḍdedes de_livreescolba.

Fonte: Nova Escola (2019c).

FIGURA 5 - Proposta com materiais tecnológicos 4

\begin{abstract}
O que fazer antes?
Contextos prévios:

Para esta proposta escolha uma história em que acontecem enganos. Elas, geralmente são caracterizadas quando algum personagem pratica uma ação mas, no enredo, fica claro que sua intenção era outra, gerando situações de tensão, medo ou humor. Preparamos uma coletânea de alguns

títulos que trazem em sua narrativa situações de engano. Você pode acessá-la aquí. * entonaçōes e as características desse tipo de enredo, garantindo a fluidez da história, encadeando os acontecimentos como sugere o escritor e fazendo mediações para as crianças pensarem sobre a relação entre as características das persos Materiais:

Para esta proposta é necessário que você selecione uma história com engano.*

Espaços:

Organize um espaço considerando que sua estrutura proporcione sentimento de acolhida e conforto para o grupo de crianças, de maneira que elas sintam-se confortáveis para acompanhar a história. Considere organizar a turma em pequenos grupos para a proposta, caso seja mais adequado para seu contexto. Para tal, garanta um planejamento em que um grupo estará com você escutando a história e o outro estará em uma proposta que já massinha.
\end{abstract}

\section{Para finalizar:}

Ao finalizar, convide as crianças para organizar o espaço que vocês utilizaram. Caso você tenha optado por dividir o grupo, após os dois grupos terem ouvido a história, convide-os, também, para a organização da atividade em que estiveram envolvidos.

\section{Desdobramentos}

Selecione outros livros de histórias com engano e realize outros momentos como este para que as crianças possam compreender progressivamente esse tipo de enredo. As crianças demonstram interesse nesses personagens que agem de uma forma ambígua e é possível explorar mais suas características, criando um repertório muito rico. Com ele, o grupo pode criar peças teatrais, recontos e filmagens das histórias com engano.*

\section{Engajando as famílias}

Escolha um momento de abertura ou encerramento de uma reunião com as famílias e faça a mesma dinâmica do plano, contando para as famílias o que são histórias de engano e apresentando o registro de como foi contar para as crianças esse tipo de repertório.

Fonte: Nova Escola (2018d).

No entanto, ainda que o uso das tecnologias digitais esteja presente nessas propostas, é relevante questionar se realmente o uso dessas tecnologias acrescentaram alguma relevância para a prática da contação de histórias. Essas propostas podem ser adaptadas para uma atividade sem o uso das tecnologias indicadas? Essas tecnologias têm relevância fundamental para a realiza- 
ção da atividade ou foram usadas apenas como um recurso a mais?

Após a análise, pudemos aventar que essas quatro propostas pedagógicas apresentadas poderiam ser feitas perfeitamente sem o uso dessas tecnologias, o que traz esses recursos apenas como um incremento pedagógico e não imprescindível para tal fim. Nesse sentido, a realização das atividades poderia ser da forma como propõe Abramovich (2009, p. 18), isto é, que contar histórias é criar todo um clima de envolvimento que pode ser introduzido apenas com a voz, dando vida à história.

Prosseguindo com os resultados da análise, identificamos que a maioria das propostas apresentam indicações de uso de tecnologias analógicas, tendo o livro como material principal. Isto posto, suspeitamos que ainda se perpetua a contação de histórias do modo tradicional, em que o contador utiliza de elementos analógicos para compor a narração da história, dando vida à narrativa.

Nesse sentido, procuramos entender o porquê de elas trazerem mais indicações de tecnologias analógicas como recursos pedagógicos, afinal, essa recorrência identificada é boa ou ruim? Além disso, outros questionamentos nos vieram à baila ao perceber essa recorrência: Qual a relevância do uso dessas tecnologias digitais para a contação de histórias na Educação Infantil? $\bigcirc$ educador está preparado para trabalhar tecnologias digitais no contexto da Educação Infantil? A familiarização quanto ao uso de tecnologias digitais a que as crianças de hoje têm acesso fora dos muros escolares está sendo acompanhada pelos professores da Educação Infantil?

O professor está se reinventando conforme os avanços tecnológicos? E a escola está preparada, dando todo suporte aos educadores e educandos?

Todas essas reflexões precisam ser feitas no âmbito da Educação Infantil, pois, ao analisar essas propostas, é preciso se pensar nas normativas da BNCC (2018) quanto à importância em trabalhar competências condizentes à inovação e tecnologias.

Esta análise possibilitou uma reflexão quanto à indicação do uso ou não de ferramentas tecnológicas digitais no âmbito educacional, mais especialmente 
na Educação Infantil, mostrando que nem sempre o uso de tecnologia vai propiciar algo diferente da proposta mais tradicional. Nessa perspectiva, Kenski (2007, p. 46) discorre que a tecnologia só é produtiva quando o educador compreende e a incorpora de forma pedagógica, entendendo que essa ferramenta deve ser usada para propiciar algum conhecimento e enriquecendo a proposta, garantindo que a ferramenta faça toda a diferença.

Portanto, é importante inovar, mas até que ponto essa tecnologia vai ser relevante à proposta escolhida pelos educadores? À vista disso, discordamos quanto ao uso de tecnologias digitais quando pensamos que uma abordagem pode ser feita perfeitamente sem essas tecnologias.

Na compreensão da autora Kenski (2007), a escola tem o papel de garantir habilidades, adotando recursos e ferramentas pedagógicas, como forma de aproximar o educador e o educando nesse novo cenário de constantes mudanças.

Sendo assim, fica evidente que as tecnologias digitais não substituem os artefatos analógicos já existentes e tradicionalmente utilizados na contação de histórias, como fantoches e fantasias, mas acrescentam e enriquecem a contação de histórias como ferramenta pedagógica, viabilizando uma possível inovação na Educação Infantil. Diante disso, apontamos que qualquer artefato tecnológico usado de forma a desenvolver conhecimento e aprendizagem é válido.

Para findar esta análise, buscamos compreender como se dá a abordagem da contação de histórias nas propostas pedagógicas. Quanto a isso, cinco propostas adotam a leitura e a contação de histórias como sinônimas, corroborando as DCNEI (2013), que trazem que a leitura escrita com crianças pequenas se dá por meio da leitura dos livros pelo educador. Na compreensão da autora Abramovich (2009), ler é entender as histórias através do autor, já para contar histórias é necessário criar, dando vida ao personagem. A autora Tahan (1961) complementa a definição de contação de histórias como sendo um ato de narrar, vivendo, conhecendo, dominando a história, usando como instrumento a voz, o gesto e o principal: "emoção e sinceridade" (p. 30).

À vista disso, podemos dizer, então, que essas cinco propostas analisadas 
tinham leitura como instrumento pedagógico e não a contação de histórias.

Portanto, vale questionar: por que as propostas pesquisadas com o verbete contação de histórias apresentaram a leitura como sinônimas? Será que a leitura pode propiciar a mesma aprendizagem que a contação de histórias? Ao contar histórias, é realmente necessário ter o livro como recurso?

Diante desses questionamentos, as DCNEI (2013) conceituam a contação de histórias e a leitura como ferramentas pedagógicas distintas, destacando que a contação de histórias se dá por meio da linguagem oral, já a leitura escrita é proporcionada por meio dos livros e da leitura.

Partindo disso, podemos dizer que leitura e contação de histórias são gêneros discursivos distintos, ainda que tenham proximidades em suas práticas: na leitura, o livro é o instrumento que o educador usará para ler a história, seguindo o contexto e sendo fiel à ideia do autor; já, no contar história, é o educador que se torna protagonista, dando vida na sua interpretação.

Nesse sentido, pode-se verificar que, nos dados analisados, a contação de histórias aparece como sinônimo de leitura e não como uma prática pedagógica diferente da leitura, como definido por Abramovich (2009).

\section{CONSIDERAÇÕES FINAIS}

Como principais resultados desta pesquisa, é possível afirmar que as tecnologias digitais foram efetivamente usadas em poucas propostas, observando-se uma prática de contação de histórias mais tradicional, o que não pode ser considerado um problema, uma vez que essa forma, já estabelecida há algum tempo, pode cumprir perfeitamente o objetivo no processo de ensino-aprendizagem. Entretanto, vale ressaltar, também, a relevância de se inserir os recursos digitais em tal prática a fim de atender as indicações da BNCC quanto à inserção de tecnologias digitais no contexto da educação básica.

Os conteúdos aqui a presentados demostram a importância da ampliação de pesquisas a serem realizadas sobre tecnologias digitais e Educação Infantil. Mais especificamente nesta pesquisa, foi utilizado como recorte a contação 
de histórias, podendo ser ampliada e investigada em outros âmbitos de ensino.

Desse modo, sugerimos que outras pesquisas sejam desenvolvidas para ampliar discussões quanto a essa temática no âmbito da Educação Infantil, bem como buscar compreender como as tecnologias digitais, tão presentes na vida cotidiana das crianças contemporâneas, podem ser eficazes no ensino-aprendizagem dos educandos.

\section{REFERÊNCIAS}

ABRAMOVICH, F. Literatura infantil gostosuras e bobices. 5. ed. São Paulo: Scipione, 2009.

BRASIL. Base Nacional Comum Curricular: competência gerais da educação. Brasília, DF: secretaria da educação, 2018. Disponível em: <http://basenacionalcomum.mec. gov.br/abase/>. Acesso em: 5 abr. 2020.

CRESWELL, John. Projeto de pesquisa: métodos qualitativos, quantitativo. 2. ed. porto alegre: Artmed, 2007.

CUPANI, Alberto. Filosofia da tecnologia: um convite. Editora da UFSC, 2016.

KENSKI, V. M. Tecnologias e ensino presencial e a distância. Campinas, São Paulo: Papirus, 2003.

Educação e Tecnologia: O novo ritmo da informação. 2. ed. São Paulo: Papirus, 2007. (Coleção papirus Educação).

NOVA ESCOLA. Atuando como personagens da história. Nova Escola. 2019. Disponível em: https://novaescola.org.br/plano-de-aula/4126/atuando-como-personagens-da-historia. Acesso em: 11 set. 2020.

Brincadeiras com linguagem: Leitura de História. Nova Escola. 2019. Disponível em: https://novaescola.org.br/plano-de-aula/4177/brincadeiras-com-linguagem-leitura-de-historia. Acesso em: 11 set. 2020.

Brincar com narrativas de histórias para bebês. Nova Escola. 2018.Disponível em: https://novaescola.org.br/plano-de-aula/3395/brincar-com-narrativas-de-histo- 
rias-para-bebes. Acesso em: 11 set. 2020.

História sonorizada. Nova Escola. 2018a. Disponível em: https://novaescola.org. br/plano-de-aula/2897/historia-sonorizada. Acesso em: 11 set. 2020.

Instigar o interesse dos bebês pelas ilustrações de história. Nova Escola. 2019. Disponível em: https://novaescola.org.br/plano-de-aula/4170/instigar-o-interesse-dos-bebes-pelas-ilustracoes-de-historias. Acesso em: 11 set. 2020.

Leitura musical para bebês. Nova Escola. 2019. Disponível em: https://novaescola.org.br/plano-de-aula/4473/leitura-musical-para-bebes. Acesso em: 11 set. 2020.

Motivar a interação dos bebês por elementos de histórias. Nova Escola. 2018. Disponível em: https://novaescola.org.br/plano-de-aula/3854/motivar-a-interacao-dos-bebes-por-elementos-de-historias. Acesso em: 11 set. 2020.

Recontando uma notícia de jornal. Nova Escola. 2019. Disponível em: https:// novaescola.org.br/plano-de-aula/4363/recontando-uma-noticia-de-jornal. Acesso em: 11 set. 2020.

Recontar um conto. Nova Escola. 2019. Disponível em: https://novaescola.org. br/plano-de-aula/4361/recontar-um-conto. Acesso em: 11 set. 2020.

Um novo final para uma história. Nova Escola. 2019. Disponível em: https:// novaescola.org.br/plano-de-aula/4848/um-novo-final-para-uma-história. Acesso em: 11 set. 2020.

TAHAN, Malba. A arte de ler e contar histórias. Rio de Janeiro: Conquista, 1961.

Uma história contada com massinha. Nova Escola. 2018b.Disponível em: https://nova escola.org.br/plano-de-aula/3890//. Acesso em: 11 set. 2020.

Explorando o texto da receita. Nova Escola.2019c. Disponível em: https://nova escola.org.br/plano-de-aula/4130//. Acesso em: 11 set. 2020.

Histórias com engano. Nova Escola.2018d. Disponível em: https://novaescola. org.br/plano-de-aula/3382/L. Acesso em: 11 set. 2020.

Linguagem oral na Educação Infantil. Nova Escola.2007. Disponível em: https://nova escola.org.br/plano-de-aula/3327//>. Acesso em: 11 set. 2020. 